\title{
The Division of Labor and
}

\section{The Theory of the Firm}

\author{
MichaEL T. RAUH \\ Kelley School of Business \\ Department of Business Economics \\ Indiana University \\ 1309 East Tenth Street \\ Bloomington, IN 47405-1701 \\ mtrauh@indiana.edu
}

We extend the classical teams framework to the case where team size is endogenous and workers can specialize within a division of labor. We consider two institutions: equaldivision partnerships and the firm with a budget-breaker. In contrast with the previous literature, we show that effort and team size in partnerships can be greater or less than first best. Our results for the firm are driven by two main insights. First, the budgetbreaker can increase effort with an increase in incentives and/or specialization. Second, incentives and employment are strategic substitutes. We show that the budget-breaker offers incentives that are weaker than first best or equal-division partnership incentives, so that shirking is more prevalent in the firm. Since incentives and team size are substitutes, the budget-breaker increases employment above the first best and partnership levels, so the firm is inefficiently large. The role of the budget-breaker is therefore to reduce agents' exposure to risk and to promote and coordinate specialization and the division of labor. The comparative statics of the firm are consistent with several institutional stylized facts (e.g., the size-wage effect) and recent organizational trends.

JEL Classifications: D02, D21, D86, L25, M5.

Keywords: budget-breaker, division of labor, endogenous team size, incentives, moral hazard, partnerships, size-wage effect, specialization, teams, theory of the firm. 
The corporation is a society which accomplishes its work through division of labor - a proposition now so much taken for granted that it is surprising to think it once represented a discovery.

Schon (1967) cited in Braverman (1974, p. 267)

\section{Introduction}

In this paper, we develop a theory of the firm where workers can specialize within a division of labor. We are concerned with the following questions. How do incentives, employment, and the division of labor differ across institutions? What is the relationship between incentives and specialization? In particular, are they complements or substitutes? What is the role of Holmström's budget-breaker when team size is endogenous? ${ }^{1}$ To answer these questions, we extend the classical teams framework in Alchian and Demsetz (1972) and Holmström (1982) using the theory of specialization and the division of labor in Becker and Murphy (1992). We show that the extended model generates predictions at odds with the classical literature but consistent with several institutional stylized facts and recent organizational trends.

We start with the first best benchmark, where a social planner chooses team size, task assignments (i.e., the division of labor), and efforts to maximize the expected total surplus. As in Becker and Murphy, an increase in team size results in greater specialization and division of labor, which raises both the marginal product of effort and expected output per worker. The first best employment level therefore balances the tradeoff between increasing returns to specialization and the transaction costs associated with larger teams.

We consider two institutions under moral hazard: the partnership and the firm with a budget-breaker. In Alchian and Demsetz, partnerships offer weak incentives and are therefore necessarily small to limit shirking. ${ }^{2}$ As in Levin and Tadelis (2005), we focus on equal-division partnerships (EDP) where revenue, tasks, and transaction costs are evenly

1 The literature on endogenous team size includes Levin and Tadelis (2005) and Liang et al. (2008). These papers do not consider the relationship between incentives and employment or the role of the budget-breaker when team size is endogenous but instead focus on other issues.

2 The literature on efficient or relatively efficient partnerships includes Rasmusen (1987), Legros and Matsushima (1991), Legros and Matthews (1993), Garicano and Santos (2004), and Levin and Tadelis (2005). 
divided among partners. ${ }^{3}$ An EDP chooses the number $n$ of partners to maximize the expected payoff of the representative partner. The relevant tradeoff differs from the first best in two respects. First, the representative partner only receives $1 / n$ of the expected surplus from the marginal hire. This $1 / n$ problem is also an important aspect of the Levin and Tadelis model and tends to make the EDP smaller than first best. But unlike their model, which focuses on worker selection issues rather than moral hazard, an increase in employment also reduces the representative partner's exposure to risk. It follows that an EDP can be larger or smaller than first best depending on the relative magnitudes of these two effects. Since the level of employment determines the degree of specialization and the marginal product of effort, optimal EDP effort exceeds the first best when an EDP is inefficiently large. In contrast with Alchian and Demsetz and Holmström, an EDP is not necessarily small nor is it necessarily characterized by weak incentives and shirking relative to the first best.

As documented by Garicano and Hubbard (2009), the average law firm in the United States is indeed quite small (3.65 lawyers) but the size distribution is highly skewed to the right, with the largest having hundreds of partners excluding associates and other lawyers. These relatively large law firms have evidently found some mechanism to address the freerider problem highlighted in the classical literature. In our model, we show that optimal EDP size is increasing in the price of output and the level of risk, which is consistent with a large number of small law firms handling low-risk, low-fee cases and a small number of large law firms handling cases with the opposite characteristics.

We then turn to the firm, where the budget-breaker chooses incentives, employment, and task assignments to maximize expected profits. Unlike an EDP, where incentives $1 / n$ and employment are inextricably linked, the budget-breaker can set the two independently. Our results for the firm are driven by two fundamental aspects of the model. First, the budget-breaker can increase effort with an increase in incentives and/or an increase in employment. This is because the expected marginal benefit of effort is the piece rate times

3 Bose, Pal, and Sappington (2010) show that equal division contracts can be optimal to prevent sabotage, Bartling and von Siemens (2010) because of inequity aversion, and in Levin and Tadelis (2005) for reasons of "stability." Encinosa, Gaynor, and Rebitzer (2007) document the prevalence of equal division contracts among medical group practices and Lang and Gordon (1995) among law firms in the form of the lock-step system. 
the marginal product of effort, which depends on the degree of specialization. An increase in incentives increases the former, while an increase in employment increases the latter. The second is that incentives and employment are substitutes, so the budget-breaker adjusts them in opposite directions. The model therefore predicts that larger firms offer weaker incentives. Indirect evidence is provided by Brown and Medoff (1989) and Rasmusen and Zenger (1990).

In standard agency theory with one agent, the principal decreases incentives below their first best (or ownership) level to reduce the agent's exposure to risk. In our model, however, the budget-breaker has a choice: she can reduce the aggregate risk premium with either weaker incentives (which reduce individual risk premia) or a smaller team size (which reduces the number of risk premia). We show that the former is optimal because (i) the aggregate risk premium is convex in incentives but only linear in employment and (ii) the marginal rate of substitution between incentives and employment implied by incentive compatibility favors employment because of increasing returns to specialization. Since the two are substitutes, the budget-breaker increases employment above the first best level while she reduces incentives. Our result that the capitalist firm promotes an excessive division of labor is also a central theme in the Marxist literature on labor processes, with some supporting evidence.

In Holmström, the budget-breaker solves the teams problem by strengthening weak partnership incentives, which contradicts the stylized fact that incentives are weak in firms (see Pendergast (1999)). In contrast, in our model the budget-breaker solves the teams problem with an increase in employment and offers incentives that are weaker than the optimal EDP incentive. The result that incentives are weaker and shirking more prevalent in the firm rather than the partnership represents a complete reversal of roles vis-à-vis the classical literature. In our model, the role of the budget-breaker is not to offer strong incentives but rather to reduce agents' exposure to risk and promote and coordinate specialization and the division of labor.

The model is consistent with several stylized facts about size-related differences across firms, where size is measured in terms of employment. First, there is some evidence that incentives decline with firm size, as noted earlier. Second, large firms tend to have more 
specialized workers, a more extensive division of labor, and higher transaction costs (e.g., more hierarchical layers and more explicit rules and procedures) as assumed in Becker and Murphy. Third, larger firms pay higher wages. Brown and Medoff (1989) show that only about half of this size-wage effect can be explained by differences in worker quality and that existing explanations cannot account for the residual. Fourth, large firms tend to operate in more concentrated industries and to be more capital intensive (Kalleberg and Van Buren (1996)). In our model, we show that an increase in price and/or an exogenous improvement in the production technology lead to an increase in employment (size), specialization, division of labor, transaction costs, and wages (expected total pay) but a decrease in incentives. The model is therefore consistent with the above stylized facts if greater concentration implies higher prices and greater capital intensity reflects investments in production technology.

In The Modern Firm, Roberts (2004) documents a major shift in firms' strategies and organizational structures driven in part by increased global competition and technological progress. Although many complementary variables and processes are involved, two key features of the new paradigm are a more intensive use of incentives and a reduced emphasis on returns to scale, specialization, and the division of labor. In our model, we show that a reduction in price and the level of risk (the variance of the productivity shock) induce stronger incentives but less specialization and division of labor. The model is therefore consistent with these trends if increased global competition corresponds to lower prices and technological progress (in the form of improved information and data-processing technology) to easier performance measurement, as Roberts himself suggests.

The plan for the rest of the paper is as follows. We characterize the first best in section 2 and introduce moral hazard in section 3. In section 4, we consider the EDP and the firm in section 5. We provide a tractable example in section 6 . Section 7 concludes.

\section{The First Best}

We start with the first best. There is a continuum $S=[0,1]$ of tasks, which permits an arbitrarily fine division of labor. Each task can be performed by at most one worker. 
Output in task $s$ is given by

$$
q_{s}=B l_{s}^{\gamma} e_{s}
$$

where $B>0$ and $0 \leq \gamma<1$ are technological parameters, $l_{s}$ is the time spent learning about the task, and $e_{s}$ is production effort. In Becker and Murphy (1992) the production function is Leontief $Q=y$, where

$$
y=\inf _{s \in S} q_{s} .
$$

To incorporate moral hazard, in this paper we consider the more general stochastic Leontief production technology $Q=y+\epsilon$, where $\epsilon$ is normally distributed with mean zero and variance $\sigma^{2}{ }^{4}$ We refer to the latter as objective risk.

Assume $n>0$ identical agents. Let $S_{i} \subseteq S$ be the set of tasks assigned to agent $i$, $T_{i s}=e_{i s}+l_{i s} i$ 's total effort in task $s \in S_{i}$, and

$$
T_{i}=\int_{S_{i}} T_{i s} d s
$$

$i$ 's total effort across all assigned tasks. We now derive the efficient allocation of a given total time $T_{i}$ across tasks in $S_{i}$. Given $T_{i s}, q_{s}$ is maximized when

$$
e_{i s}=\frac{T_{i s}}{1+\gamma}
$$

and $l_{i s}=T_{i s}-e_{i s}$. Substituting into (1),

$$
q_{s}=\frac{B}{\gamma}\left(\frac{\gamma}{1+\gamma}\right)^{1+\gamma} T_{i s}^{1+\gamma} .
$$

To maximize agent $i$ 's component of expected output

$$
y_{i}=\inf _{s \in S_{i}} q_{s},
$$

$T_{i}$ should be allocated equally across assigned tasks. Let $\rho_{i}$ be the proportion of tasks assigned to $i$ (i.e., the measure of $S_{i}$ ). Substituting $T_{i s}=T_{i} / \rho_{i}$ into (5),

$$
y_{i}=\frac{B}{\gamma}\left(\frac{\gamma}{1+\gamma}\right)^{1+\gamma}\left(\frac{T_{i}}{\rho_{i}}\right)^{1+\gamma} \text {. }
$$

4 Output is therefore negative with positive probability. As in Holmström and Milgrom (1991), we could assume instead that output is deterministic $Q=y$ but non-contractible, and that contracts can only be based on the signal $y+\epsilon$ (which can legitimately take negative values), where $\epsilon$ has the same properties. Our results would be unaffected. 
To simplify expressions, we define $A>0$ and $1 \leq \theta<2$ such that

$$
y_{i}=\frac{A}{\theta}\left(\frac{T_{i}}{\rho_{i}}\right)^{\theta} \text {. }
$$

This production technology has two features traditionally associated with specialization and the division of labor which will be important in what follows. First, (8) exhibits increasing marginal and average returns to effort $T_{i}$ when $\theta>1$. Second, these returns are increasing in the degree $1 / \rho_{i}$ of specialization.

Let $N>1$ be the size of the labor pool, while $0 \leq n \leq N$ is the number actually employed. All agents are identical and we ignore integer constraints throughout the paper. In Becker and Murphy, agents are endowed with a fixed unit of labor. In this paper we allow for elastic supply, where $C\left(T_{i}\right)$ is the cost of effort. Following Becker and Murphy, we assume that larger teams incur higher transaction costs $K(k, n)$, where $k>0$ is a parameter which increases marginal transaction costs. These include the costs of communicating task assignments and coordinating the assembly of intermediate outputs into final output. We assume $C$ and $K$ satisfy the following properties.

Assumption 1. (i) $C$ is three times differentiable and $C^{\prime}(0)=0$. Let

$$
f\left(T_{i}\right)=C^{\prime}\left(T_{i}\right) / T_{i}^{\theta-1}
$$

(ii) $f(0)=0, f^{\prime}>0$ on $(0, \infty)$, and $f\left(T_{i}\right) \rightarrow \infty$ as $T_{i} \rightarrow \infty$. (iii) $K(k, 0)=K_{n}(k, 0)=0$, $K_{n}>0$ for all $n>0$, and $K_{n n}>0$ for all $n \geq 0$. (iv) $K_{k n} \geq 0$.

The expression for $f$ in (9) is the ratio of the marginal cost and expected marginal productivity of effort (see (8)) after normalizing for $A$ and the task assignment $\rho_{i}$. Since expected output increases at an increasing rate, the agents' optimal efforts will be infinite unless marginal costs increase sufficiently fast. The requirement in (ii) that $f$ is increasing and unbounded ensures this. The rest of the assumptions are standard. The following common functional forms satisfy all of the above conditions

$$
\begin{gathered}
C\left(T_{i}\right)=(1 / 2) T_{i}^{2} \\
K(k, n)=(1 / 2) k n^{2} .
\end{gathered}
$$


Let $p>0$ be the price of output. The first best or social planner's problem is to choose the team size $n$, task assignments $\left\{\rho_{i}\right\}_{i=1}^{n}$, and efforts $\left\{T_{i}\right\}_{i=1}^{n}$ to maximize the expected total surplus

$$
V\left(n,\left\{\rho_{i}\right\},\left\{T_{i}\right\}\right)=p y-\sum_{i} C\left(T_{i}\right)-K(k, n)
$$

subject to the constraint $0 \leq n \leq N$. Let $n_{f}$ denote the first best optimal team size.

Proposition 1. (i) Given $0<n \leq N$, the first best total effort is

$$
T(n)=g\left(p A n^{\theta-1}\right)
$$

where $g=f^{-1}$, and the first best task assignment is an equal division of labor $\rho_{i}=1 / n$ for all $i$. (ii) Assume (10) and (11). The break-even employment level is

$$
n_{f}^{0}=\left[\frac{(2-\theta)(A p)^{\frac{2}{2-\theta}}}{\theta k}\right]^{\frac{2-\theta}{4-3 \theta}} .
$$

If $4 / 3<\theta<2$ then $n_{f}=N$ when $n_{f}^{0} \leq N$ and $n_{f}=0$ otherwise. Let

$$
n_{f}^{c}=\left[\frac{(A p)^{2}}{(2 k)^{2-\theta}}\right]^{\frac{1}{4-3 \theta}} \text {. }
$$

If $1 \leq \theta<4 / 3$ and

$$
\left(\frac{2-\theta}{\theta}\right)(A p)^{\frac{2}{2-\theta}} \geq k
$$

then $n_{f}=n_{f}^{c}$ when $n_{f}^{c} \leq N$ and $n_{f}=N$ otherwise.

The first result gives the first best total effort and division of labor in the usual case where team size $n$ is given and exogenous. The first best effort $T(n)$ in (13) is increasing in $n$ because a larger team is more specialized with higher expected marginal productivity, so the planner chooses greater effort. Substituting $\rho_{i}=1 / n$ and $T(n)$ into (12), we obtain the expected total surplus solely as a function of employment

$$
V(n)=V[n,\{1 / n\},\{T(n)\}] .
$$

The first best employment level $n_{f}$ maximizes (17) subject to the constraint $0 \leq n \leq N$. 
The rest of Proposition 1 characterizes the first best employment level $n_{f}$ under the specific functional forms in (10) and (11). The central tradeoff is between the increasing returns to specialization and the transaction costs associated with larger teams. We refer to this as the Becker-Murphy tradeoff, which will be augmented under moral hazard. When the returns to specialization are sufficiently high $4 / 3<\theta<2$, expected total surplus $V(n)$ is U-shaped, where $n_{f}^{c}$ in (15) is the global minimizer and $n_{f}^{0}$ in (14) is the break-even employment level. In that case, the planner shuts down when $N<n_{f}^{0}$ and employs the entire labor pool otherwise. When returns are sufficiently low $1 \leq \theta<4 / 3$, expected total surplus is hill-shaped with a global unconstrained maximum at $n_{f}^{c}$, which is the global constrained maximizer when $n_{f}^{c} \leq N$. The condition in (16) ensures that expected total surplus is positive at $n=1$, so the planner operates. Note that $n_{f}^{c}$ is increasing in $A$ and $p$ and decreasing in the transaction cost parameter $k$ as is intuitive. Since the case where increasing returns dominate is not very interesting, we assume $1 \leq \theta<4 / 3$ and $N=\infty$ for the rest of the paper.

The model therefore predicts that larger teams will be more specialized, with a more extensive division of labor and higher transaction costs. Since this result follows directly from efficiency in production, it is not institution-specific and will also hold for partnerships and firms below. These predictions are consistent with the robust empirical finding that firm size is positively correlated with division of labor and vertical differentiation (i.e., the number of hierarchical layers); see Beyer and Trice (1979), Kalleberg and Van Buren (1996), and the survey by Carter and Keon (1986).

\section{Moral Hazard}

We now introduce moral hazard into the Becker-Murphy framework. Following the teams literature, we assume individual performance measures are unavailable and that only final output $Q$ is contractible. We compare two institutions: (i) a firm with a budget-breaker (referred to as simply the firm), who offers a linear contract $I_{i}=\alpha_{i}+\beta_{i} Q$ to each worker $i$, where $I_{i}$ is income, $\alpha_{i}$ a lump sum (which can be negative), and $\beta_{i}$ the incentive and (ii) an equal-division partnership (EDP) with zero lump-sum transfers $\alpha_{i}=0$ and an equal 
division of labor $\rho_{i}=1 / n$, revenue $\beta_{i}=p / n$, and transaction costs. ${ }^{5}$

We do not offer a novel explanation for the existence of partnerships. If the parameters $(A, k, p, \theta)$ are the same for both institutions then EDP expected profits cannot be higher than the firm because the budget-breaker is free to choose the same employment level, incentive contract, and task assignments. The EDP is therefore inefficient unless the parameters favor it. For example, Garicano and Santos (2004) show that partnerships can address the moral hazard and adverse selection problems associated with matching workers to opportunities (referrals) more effectively than market arrangements. Levin and Tadelis (2005) show that an EDP hires better workers than a budget-breaker and therefore may be more efficient when consumers are uncertain about product quality. In our model, the productivity parameter $A$ and $p$ may be higher in an EDP for similar reasons.

The agents' utility functions are negative exponential

$$
-\exp \left\{-r\left[I_{i}-C\left(T_{i}\right)\right]\right\}
$$

where $r>0$ is the coefficient of absolute risk aversion. The corresponding certainty equivalent is given by 6

$$
U_{i}=\alpha_{i}+\beta_{i} y-C\left(T_{i}\right)-(1 / 2) s \beta_{i}^{2}
$$

The first two terms constitute expected income as a function of expected output. The final term is the agent's risk premium, which reflects the disutility of risk. It is increasing in both subjective risk $s=r \sigma^{2}$ (objective risk scaled by the agents' risk aversion) and incentives because stronger incentives link income more closely to stochastic final output.

The timing of the game is as follows. (i) A budget-breaker chooses the number $n$ of workers, the contracts $\left\{\left(\alpha_{i}, \beta_{i}\right)\right\}$, and task assignments $\left\{\rho_{i}\right\}$. In an EDP, the sole choice variable is partnership size $n$ because incentives $\beta_{i}=p / n$ and task assignments $\rho_{i}=1 / n$ are otherwise fixed institutional features. (ii) Agents who receive offers decide whether or not to accept them. We assume that all agents have an outside option of zero and indifferent

5 Linear contracts are quite common in actual organizations (see footnote 3) and can be justified on various grounds. In the case of a single agent with limited liability, Bose, Pal, and Sappington (2011) show that the optimal linear contract secures at least $90 \%$ of the expected profits of the optimal nonlinear second best contract. A linear contract will therefore be optimal when transaction costs are sufficiently increasing in contractual complexity.

6 Bolton and Dewatripont (2005, p. 137) provide a detailed derivation. 
agents accept. (iii) The agents who accepted choose their efforts non-cooperatively. (iv) Output is realized and the contract is executed. A budget-breaker chooses $n$ to maximize her expected profits. As in Lang and Gordon (1995) and Levin and Tadelis, an EDP chooses $n$ to maximize the representative partner's expected payoff. The following result characterizes the set of equilibria in efforts in stage (iii) for both institutions.

Lemma 1. (i) Given $n>0,\left\{\rho_{i}\right\}$, and $\left\{\beta_{i}\right\}$ such that $\rho_{i}>0$ and $\beta_{i}>0$ for all $i$, there is a continuum of equilibria in the third stage of the game, one of which is Pareto dominant from the perspective of the workers. ${ }^{7}$ (ii) If $\beta_{i}=\beta$ and $\rho_{i}=1 / n$ for all $i$, the Pareto dominant equilibrium is

$$
T_{i}=g\left(A n^{\theta} \beta\right)
$$

for all $i$. (iii) [Legros and Matthews (1993)] In an EDP, the effort-employment relationship is the same as the first best (13) in the Pareto dominant equilibrium.

The first result follows directly from the stochastic Leontief production technology. Clearly, one equilibrium is for all agents to exert zero effort. In the proof (see the appendix), we show that the Pareto dominant equilibrium is the effort profile which generates the highest incentive compatible level of expected output, with a continuum of equilibria in between. From now on, we assume that all players prior to stage (iii) believe that the Pareto dominant equilibrium will obtain with probability one. This is the most reasonable assumption to make, especially in the firm where all parties (including the budget-breaker) have a similar incentive to coordinate and where the budget-breaker as the central party to all contracts can easily perform this function.

The second result is one of the main insights of the paper: an increase in effort can be achieved with an increase in incentives $\beta$ and/or an increase in employment $n$. This is because the agents' expected marginal benefit of effort is the piece rate $\beta$ times the expected marginal product of effort. Given an equal division of labor, an increase in employment leads to a greater degree of specialization and higher expected marginal productivity and therefore induces greater effort.

7 I.e., all workers are strictly better off as compared with any other equilibrium. 
The third result is similar to Legros and Matthews (1993, Example B), with one crucial distinction. In the case where $n$ is exogenous, Legros and Matthews show that partnerships can achieve the first best under general conditions which include a deterministic Leontief production function. The difference is that team size is endogenous in our model and EDP efforts are first best if and only if EDP employment is first best. In the next section, we show that this is generally not the case. The result does show, however, that equal-division incentives are high-powered or market incentives in the sense that they induce the first best effort-employment relationship.

\section{Equal Division Partnerships}

In an EDP, there are no lump-sum transfers and revenue, tasks, and transaction costs are all shared equally. After substituting the incentive compatibility constraint $T(n)$ in $(13)$, the certainty equivalent payoff of the representative partner becomes

$$
\begin{aligned}
U^{p}(n) & =(1 / n) p y-C[T(n)]-(1 / 2) s(p / n)^{2}-(1 / n) K(k, n) \\
& =(1 / n) V(n)-(1 / 2) s(p / n)^{2}
\end{aligned}
$$

where $V(n)$ is the first best expected surplus defined in (17). Let $n_{p}$ denote the optimal EDP employment level (the maximizer for $(21)$ ) and $T_{p}=T\left(n_{p}\right)$ optimal EDP effort. We first consider the case of zero subjective risk (i.e., risk neutrality and/or zero objective risk) so we can compare an EDP in our model with the deterministic cases in Holmström and Legros and Matthews where team size is exogenous.

Lemma 2. Assume $s=0$ and (10) and (11). If $1<\theta<4 / 3$ and (16) holds then

$$
n_{p}=\left[\frac{2(A p)^{\frac{2}{2-\theta}}(\theta-1)}{\theta k}\right]^{\frac{2-\theta}{4-3 \theta}}
$$

where $n_{p}<n_{f}$ and $T_{p}<T_{f}$.

When subjective risk is zero, we obtain a sharp result: an EDP is inefficiently small with shirking relative to the first best. Although consistent with Alchian and Demsetz, where partnerships are small to limit free-riding, the logic is actually the reverse. As in 
Legros and Matthews, the effort-employment relationship $T(n)$ is the same as the first best. It follows that the immediate distortion is not moral hazard but rather the Levin-Tadelis $1 / n$ problem which distorts the Becker-Murphy tradeoff $V(n)$ in $(21)$ and causes an EDP to be inefficiently small. Unlike Levin and Tadelis, who focus on worker selection issues rather than moral hazard, in our model this results in less specialization, lower expected productivity, and therefore less effort. In Alchian and Demsetz, partnerships are small to control shirking, whereas in our model shirking occurs because partnerships are small. The result also shows that the conclusions in Legros and Matthews can break down when team size is endogenous. An EDP is efficient when team size is exogenous, but inefficient otherwise because EDP employment is less than first best.

We now return to the case of positive subjective risk, which introduces a risk-reward tradeoff into (21), in addition to the Becker-Murphy tradeoff $V(n)$ and the $1 / n$ problem.

Proposition 2. Assume $1<\theta<4 / 3$, (10) and (11), and

$$
\left(\frac{2-\theta}{\theta}\right)(A p)^{\frac{2}{2-\theta}} \geq k+s p^{2}
$$

(i) There is a unique solution $n_{p}>0$ for (21) which is increasing in $A, p$, and $s$ and decreasing in $k$. (ii) (comparison with the first best)

$$
\operatorname{sign}\left(n_{f}-n_{p}\right)=\operatorname{sign}\left(T_{f}-T_{p}\right)=\operatorname{sign}\left\{\frac{4-3 \theta}{\theta}\left[\frac{A^{6} p^{3 \theta-1}}{2^{2(5-3 \theta)} k^{2}}\right]^{\frac{1}{4-3 \theta}}-s p^{2}\right\}
$$

A unique interior solution exists, but we can no longer provide a closed-form expression for it as in Lemma 2. The comparative statics for $A, k$, and $p$ are intuitively clear and already reflected in (22). The new result is that an increase in subjective risk $s$ leads to an increase in optimal EDP employment, which reduces the equal-division incentive and hence the representative partner's exposure to risk. The comparison with the first best shows that the characterization of the partnership in Alchian and Demsetz as inefficiently small and prone to shirking is not robust and depends on $s$. In particular, an EDP is inefficiently large when subjective risk is sufficiently high in the sense of (24). In that case, optimal EDP effort will exceed the first best because effort (13) is increasing in employment. The condition in (23) ensures $U^{p} \geq 0$ at the optimum. 
Garicano and Hubbard (2009) study the division of labor in firms and markets using data on law partnerships. They distinguish between individual and ex post law fields like criminal law, where the client usually contacts the firm after the fact, and ex ante fields like banking, corporate, and tax law, where the client is often proactive. They find that the division of labor among individual and ex post fields is coordinated by the market, but within the firm among ex ante fields. Since ex ante fields differ substantively from one another with positively correlated demands, explanations based on mutual monitoring and risk-sharing seem implausible. ${ }^{8}$ A more likely explanation is the theory of referrals in Garicano and Santos (2004), which shows that partnerships can address the adverse selection and moral hazard issues associated with matching individuals to tasks more efficiently than the market. These issues are more salient in ex ante fields where the client's problem often requires an initial diagnosis and subsequent referral by an expert.

Our model is highly complementary with theirs in the sense that an institution which is superior at allocating individuals to tasks based on comparative advantage should also be superior at coordinating a division of labor in a team production context. Indeed, Lang and Gordon (1995) note that complex corporate cases usually involve teams of lawyers from different specialities. While the fact that the average law firm in the United States is quite small (3.65 lawyers) is consistent with the free-riding explanation in Alchian and Demsetz, the fact that the size distribution is highly skewed to the right, with the largest law firms having a thousand or more partners, suggests that other forces may be at work. From the perspective of Proposition 2, this is consistent with a large number of small law firms handling low-risk $\sigma^{2}$ low-reward $p$ cases with a minimal division of labor, and a small number of large law firms handling cases of the opposite type with an extensive division of labor.

\section{The Firm}

We now introduce a budget-breaker. The firm's profit equals revenue less the payments to

8 It is important to distinguish between risk-sharing in the portfolio sense (which is how Garicano and Hubbard use the term) and the risk-reward tradeoff. Indeed, in our model the demands for the outputs of individual workers are perfectly positively correlated, but an increase in team size nevertheless reduces the workers' exposure to risk. Gaynor and Gertler (1995) find evidence for the risk-reward tradeoff in medical partnerships, in that incentives are decreasing in the average risk aversion in the group. 
workers and transaction costs

$$
p Q-\sum_{i} I_{i}-K(k, n)
$$

The budget-breaker chooses the number $n$ of workers, the contracts $\left\{\left(\alpha_{i}, \beta_{i}\right)\right\}$, and task assignments $\left\{\rho_{i}\right\}$ to maximize expected profits

$$
p y-\sum_{i}\left(\alpha_{i}+\beta_{i} y\right)-K(k, n)
$$

subject to incentive compatibility (the Pareto dominant equilibrium in Lemma 1) and the participation constraints $U_{i} \geq 0$, where $U_{i}$ was defined in (19). The lump sums $\alpha_{i}$ are chosen to make the participation constraints bind. Substituting these into (26),

$$
\Pi\left(n,\left\{\beta_{i}\right\},\left\{\rho_{i}\right\},\left\{T_{i}\right\}\right)=p y-\sum_{i} C\left(T_{i}\right)-(1 / 2) s \sum_{i} \beta_{i}^{2}-K(k, n) .
$$

We assume the following condition for the rest of the paper.

Assumption 2. For all $1 \leq \theta<4 / 3$ and $T_{i}>0$,

$$
4 \theta f^{\prime}+T_{i} f^{\prime \prime} \geq 0
$$

This condition is crucial for our next result, which simplifies the analysis considerably. Note that the quadratic cost function in (10) satisfies both Assumptions 1 and 2.

Lemma 3. Assume a given number $n>0$ of agents. Given any profile of incentives $\left\{\beta_{i}\right\}$ and task assignments $\left\{\rho_{i}\right\}$, the budget-breaker can achieve the same expected output but higher expected profits with an equal division of labor and an incentive $\beta$ which is the same for all agents.

The intuition is as follows. Let $\left\{T_{i}\right\}$ be the Pareto dominant equilibrium corresponding to the given incentives $\left\{\beta_{i}\right\}$ and task assignment $\left\{\rho_{i}\right\}$. Since expected output is Leontief, it may be possible to implement $\left\{T_{i}\right\}$ with weaker incentives. Let $\left\{\beta_{i}\left(\rho_{i}\right)\right\}$ be the weakest incentive profile that implements $\left\{T_{i}\right\}$ (see (A.17) in the appendix). If necessary, the budget-breaker can increase expected profit by reducing the original incentives to $\left\{\beta_{i}\left(\rho_{i}\right)\right\}$. The minimum incentive $\beta_{i}\left(\rho_{i}\right)$ is increasing in $\rho_{i}$ because an increase in the latter reduces 
specialization and expected marginal productivity and therefore requires an increase in incentives to maintain the desired effort $T_{i}$. As shown in the proof, (28) ensures that $\beta_{i}\left(\rho_{i}\right)^{2}$ is a convex function of $\rho_{i}$, so an increase in $\rho_{i}$ above $1 / n$ increases the risk premium in (27) at an increasing rate. The budget-breaker therefore chooses an equal division of labor. The idea of the proof is to show that $\sum_{i} \beta_{i}\left(\rho_{i}\right)^{2}$ behaves like a Herfindahl index with "market shares" $\rho_{i}$, so "concentration" is minimized with equal market shares. This implies the same incentive for all agents. The main consequence is that we can re-write (27) as the much more manageable

$$
\Pi(\beta, n, T)=p \frac{A}{\theta}(n T)^{\theta}-n\left[C(T)+(1 / 2) s \beta^{2}\right]-K(k, n) .
$$

Proposition 3 below formalizes another central insight of the paper. Its statement involves concepts from lattice programming formally defined in the appendix. Let $F(x, a)$ be a twice continuously differentiable function of a vector $x$ of choice variables and a vector $a$ of parameters. The variables $x_{i}$ and $x_{j}$ are strategic complements if $\partial^{2} F / \partial x_{i} \partial x_{j} \geq 0$ on the entire domain of $F$, so an increase in $x_{i}$ increases the marginal effect of $x_{j}$ and vice-versa. The function $F$ is supermodular in $x$ with increasing differences in $(x, a)$ if $\partial^{2} F / \partial x_{i} \partial x_{j} \geq 0$ for all $i \neq j$ and $\partial^{2} F / \partial a_{k} \partial x_{i} \geq 0$ for all $i$ and $k$. In that case, an increase in the parameter $a_{k}$ will induce an increase in the maximizers $x_{i}$ for all $i$. If $\partial^{2} F / \partial x_{i} \partial x_{j} \leq 0$ then $x_{i}$ and $x_{j}$ are strategic substitutes. After a change of variable, $x_{i}$ and $z_{j}=1 / x_{j}$ are strategic complements.

We want to show that employment $n$ and effort $T$ are strategic complements, while $\beta$ is a substitute for $n$ and $T$. The problem is that the relevant cross-partials do not have the appropriate signs on the entire domain of $\Pi$, which necessitates the more complicated statement below. What we can show is that there exists a subset $S$ of the constraint set which has the following properties: (i) $S$ is a lattice (defined in the appendix), (ii) the optimum lies in $S$ for all permissible values of the parameters $(A, k, p, s)$, and (iii) $\Pi$ is supermodular in $(z, n, T)$ with increasing differences in $(z, n, T)$ and $(p, w)$ on $S$ (but not on the entire domain of $\Pi$ ), where $z=1 / \beta$ and $w=1 / k$. It follows that incentives and employment are substitutes at the optimum, so a reduction in price or an increase in communication costs induces the budget-breaker to reduce employment and increase incentives. 
Proposition 3. Assume $1 \leq \theta<4 / 3$ and that the firm's problem has a unique interior solution $\left(\beta_{b}, n_{b}, T_{b}\right)$ for all $A, k, p, s>0$. Let $w=1 / k, z=1 / \beta$, and

$$
h(z, n)=\min \left\{g\left(A n^{\theta}(1 / z)\right), g\left(A n^{\theta-1}\right)\right\} .
$$

(i) The set

$$
S=\{(z, n, T) \mid z>0, n>0, \text { and } T=h(z, n)\}
$$

is a lattice which contains the optimum for all $A, k, p, s>0$. (ii) $\Pi$ in (29) is supermodular in $(z, n, T)$ with increasing differences in $(z, n, T)$ and $(p, w)$ for all

$$
(z, n, T, p, w) \in S \times[(1 / \theta), \infty) \times(0, \infty)
$$

(iii) In particular, $n$ and $T$ are increasing and $\beta$ decreasing in $p$ and $w$.

To understand the mechanics of the model, consider an increase in price $p$. From the incentive compatibility constraint (20), the budget-breaker can increase expected output by increasing employment $n$ and/or increasing incentives $\beta$. In the standard linear model with one agent and quadratic cost of effort (10), the optimal incentive is $\beta=p /(1+s)$ (see Bolton and Dewatripont (2005, p. 139)), so an increase in price leads to an increase in incentives. In our model, however, the budget-breaker has a choice and instead increases employment. This follows from two aspects of the structure of expected profits in (29). First, incentives and employment are strategic substitutes in terms of the aggregate risk premium, so an increase in one will be associated with a decrease in the other to reduce the agents' exposure to risk. Second, employment and effort are strategic complements in the production function, so the budget-breaker will change both in the same direction when the price is high enough (note the condition $p \geq 1 / \theta$ in (32)). Since the budget-breaker desires more output, she will increase $n$ and $T$ and reduce $\beta$ to reduce the aggregate risk premium. The overall effect of the increase in specialization and reduction in incentives is to increase effort.

The closest result in the literature is Lin (1997), who considers two risk-neutral agents and a deterministic production function which can be linear in efforts or Leontief. He shows that the incentives which implement the first best are lower in the Leontief case 
where efforts are complementary, so incentives have positive spillovers. He also shows that the first best incentives are lower when the number of agents is exogenously increased from two to four. The same effect is evident in (20), augmented by the increasing returns $\theta$ to specialization, where a given level of effort can be achieved with lower incentives when employment is higher. In our model with uncertainty and risk aversion, incentives and employment are substitutes not because of the Lin effect but rather because of their relationship with the aggregate risk premium.

The existing evidence is highly indirect but nevertheless consistent with our prediction that larger firms offer weaker incentives (i.e., that $n$ and $\beta$ are substitutes). Rasmusen and Zenger (1990) show (their lemma 1) that smaller firms are more efficient at detecting shirking in a purely statistical sense (they do not model optimal incentives or employment). They therefore predict that small firms will compensate more on the basis of performance, while large firms will emphasize easily observable employee characteristics such as tenure. Empirically, they find that the positive relationship between wages and tenure is stronger in large firms. Furthermore, regressions of weekly earnings on tenure, outside experience, and education have a larger residual variance for small firms, which is consistent with the hypothesis that small firms reward performance instead. Brown and Medoff (1989, p. 1054) find that the standard deviation of wages is smaller at large firms after controlling for the wider range of occupations, which is also consistent with weaker incentives.

For purposes of comparison with the first best and an EDP, we express expected profits solely in terms of $n$ and $T$. Substituting the incentive compatibility constraint (20),

$$
\Pi(n, T)=p \frac{A}{\theta}(n T)^{\theta}-n\left\{C(T)+(1 / 2) s\left[\frac{f(T)}{A n^{\theta}}\right]^{2}\right\}-K(k, n) .
$$

The budget-breaker therefore chooses $n \geq 0$ and $T \geq 0$ to maximize (32). We now contrast the firm's optimum $\left(n_{b}, T_{b}\right)$ with the first best solution $\left(n_{f}, T_{f}\right)$ under some basic regularity conditions.

Proposition 4. Assume a unique interior optimum $\left(n_{i}, T_{i}\right)$ for $i=b, f$. If there exists an open convex subset of $[0, \infty) \times[0, \infty)$ which contains both solutions and where (33) is strictly concave then $n_{b}>n_{f}, T_{b}<T_{f}$, and $\beta_{b}<p / n_{f}$. 
According to this result, the firm is inefficiently large $n_{b}>n_{f}$ with less than first best effort $T_{b}<T_{f}$. Although the budget-breaker could offer the incentive $\beta=p / n_{f}$ which implements the first best effort in (13), she instead offers weaker incentives to reduce the agents' exposure to risk. This result generalizes the standard risk-reward tradeoff in the sense that now the budget-breaker has a choice: she can reduce the aggregate risk premium in (29) with high incentives and low employment or the reverse. In our model, the budgetbreaker chooses high employment and low incentives for two reasons. First, the marginal rate of substitution for the iso-effort curve defined by the incentive compatibility constraint (20) favors high employment when there are increasing returns $\theta>1$ to specialization. To see this, consider the option of high incentives and low employment. When $\theta>1$, the budget-breaker can achieve the same effort level with a lower aggregate risk premium with a large decrease in incentives and a small increase in employment. A similar statement holds for the high employment option, but the marginal rate of substitution is smaller in absolute terms. Second, the aggregate risk premium is convex in incentives but only linear in team size, which also favors the high employment option. The overall effect of weaker incentives but greater specialization is shirking relative to the first best.

The assumed regularity conditions are fairly mild. Note that we do not require global strict concavity of (33), which generally fails, but rather local strict concavity on a convex neighborhood which contains both solutions. Under these assumptions, we can use the relevant first-order conditions to compare the firm's optimum with the first best. An example is provided in the next section.

We therefore obtain the novel result that firms promote excessive specialization and division of labor relative to the first best. As far as we know, the only literature which makes similar claims is the Marxist literature on labor processes initiated by Braverman (1974). Braverman's main contention is that capitalists use machinery and the division of labor not only to improve productivity, but also to divide the work into simpler components so they can reduce wages and achieve greater control over the production process. In contrast, in the example in the next section we show that an increase in the productivity parameter $A$ (e.g., an investment in machinery) leads to an increase in specialization and the division of labor and a reduction in incentives, but an increase in wages (i.e., expected 
pay). Wallace and Kalleberg (1982) and Borghans and Bas ter Weel (2006) (in the case of fast computer adopters) find evidence for Braverman's de-skilling hypothesis, although the latter paper does not belong to the Marxist literature and is seemingly unaware of it.

Following Holmström (1982), we now compare firms and partnerships. In Holmström, the partnership is defined as a budget-balanced sharing rule, where the payments to workers sum to revenue. An example is the equal-division sharing rule in this paper. He first shows (his theorem 1) that budget-balanced sharing rules cannot achieve the first best because agents receive less than their full marginal products. As in Alchian and Demsetz, the partnership is therefore prone to free-riding.

\begin{abstract}
The result indicates that in closed (budget-balanced) organizations like a labor-managed firm or a partnership, free-rider problems are likely to lead to an insufficient supply of productive inputs like effort. This observation is the starting point for Alchian and Demsetz' (1972) well-known theory of the firm. They argue that the inefficiency of a partnership will cause an organizational change. To secure a sufficient supply of effort, firms should hire a principal to monitor the behavior of agents. The monitor should be given title to the net earnings of the firm so that he has the proper incentives to work. Such an arrangement will restore efficiency. At the same time, it will change the partnership into a capitalistic firm with the monitor acting effectively as the owner. There is a simpler solution, however, at least under certainty.
\end{abstract}

(p. 327)

The simpler solution is a Mirrlees contract, which imposes group penalties when a specified output level is not achieved (theorem 2). Alternatively, the budget-breaker can implement the first best with ownership incentives (see Bolton and Dewatripont (2005, p. 302-3)), where agents are paid their full marginal products and the principal extracts the entire surplus with up-front fees. In the case of uncertainty, a Mirrlees contract can approximate the first best arbitrarily closely (theorem 3). In each case, the role of the budget-breaker is the same: to provide strong incentives.

Empirically, the role of the budget-breaker in Holmström conflicts with the well-known stylized fact that incentives are weak in firms (see Prendergast (1999)). From a theoretical perspective, we now show that the result is not robust and that the role of the budgetbreaker is fundamentally altered when employment as well as incentives is chosen in the context of uncertainty, specialization, and the division of labor.

Proposition 5. Assume a unique interior optimum $\left(n_{i}, T_{i}\right)$ for $i=b, p$ and $1<\theta<4 / 3$ or $U^{p}>0$ at the EDP optimum. If there exists an open convex subset of $[0, \infty) \times[0, \infty)$ 
which contains both solutions and where (33) is strictly concave then $n_{b}>n_{p}, \beta_{b}<p / n_{p}$, and $T_{b}<T_{p}$.

It is important to distinguish this result from Proposition 4 above: the present one is stronger when an EDP is inefficiently large $n_{p}>n_{f}$ and weaker otherwise. The result that partnerships are smaller than firms $n_{p}<n_{b}$ is consistent with Alchian and Demsetz, but the fact that incentives are weaker $\beta_{b}<p / n_{p}$ and shirking more prevalent $T_{b}<T_{p}$ in the firm represents a complete reversal from Holmström. In our model, the role of the budget-breaker is to promote and coordinate specialization and the division of labor and to reduce the agents' exposure to risk rather than to provide strong incentives.

The first element in the intuition is that the budget-breaker can choose incentives and team size independently, whereas in an EDP the employment decision simultaneously determines equal-division incentives. The second is the insight in Legros and Matthews that partnerships offer first best incentives when output is deterministic Leontief and team size is exogenous. Note that the Leontief assumption is quite natural in a division of labor context, where the production process is broken into smaller components which are subsequently assembled into final output. Likewise, in our model the EDP incentive induces the same effort-employment relationship as the first best (Lemma 1(iii)). Unlike Alchian and Demsetz and Holmström, the problem is not that EDP incentives are too weak, but that they are too strong. The budget-breaker therefore offers weaker incentives to reduce the agents' exposure to risk. At the same time, unencumbered by the $1 / n$ problem, the budget-breaker increases employment above the EDP level, so that firms exhibit a greater degree of specialization and division of labor. The overall effect of weaker incentives and greater employment is shirking relative to an EDP.

\section{Example and Further Comparative Statics}

This example serves two purposes. First, it provides an instance where the regularity conditions in Propositions 4 and 5 are satisfied and can be given economic content. Second, it allows us to derive further comparative statics results which can be compared with several institutional stylized facts and recent organizational trends. 
Assume $\theta=1$ and the functional forms in (10) and (11). From (13) and (15), the first best solution is $T_{f}=A p$ and $n_{f}=(A p)^{2} /(2 k)$. In an EDP, the certainty equivalent payoff of the representative partner is

$$
U^{p}=p A T-(1 / 2) T^{2}-(1 / 2) s(p / n)^{2}-(1 / 2) k n,
$$

with solution $T_{p}=T_{f}=A p$ and $n_{p}=\left(2 p^{2} s / k\right)^{1 / 3}$. Note that most of Proposition 2 above continues to hold when $\theta=1$. In particular, $n_{p}$ is increasing in price $p$ and subjective risk $s$ and decreasing in the transaction cost parameter $k$. Furthermore, $n_{p}<n_{f}$ when $s$ is sufficiently low and inefficiently large otherwise. If

$$
A^{6} p^{4} \geq(27 / 4) s k^{2}
$$

then $U_{p} \geq 0$ at the optimum and the EDP will operate. The budget-breaker's expected profit is

$$
\Pi=p A n T-n\left[(1 / 2) T^{2}+(1 / 2) s \beta^{2}\right]-(1 / 2) k n^{2} .
$$

From (20), the incentive compatibility constraint is $T=A n \beta$.

Lemma 4. (i) If

$$
A^{6} p^{4}>4 s k^{2}
$$

then in this example the budget-breaker's problem has a unique interior solution with positive expected profits. (ii) If (35) holds and $s$ is sufficiently small then there exists an open convex subset of $[0, \infty) \times[0, \infty)$ which contains $\left(n_{i}, T_{i}\right)$ for $i=b, f, p$ and where (33) is strictly concave.

In the proof, we show that

$$
n>\frac{(A p-T)^{2}}{k}
$$

is a sufficient condition for the firm's expected profits in (33) to be strictly concave in $n$ and $T$. As required, (38) defines an open convex subset of the nonnegative orthant. Since $T_{f}=T_{p}=A p$, the first best and EDP solutions clearly satisfy the condition. Furthermore, (38) does not depend on $s$ and $\left(n_{b}, T_{b}\right) \rightarrow\left(n_{f}, T_{f}\right)$ as $s \rightarrow 0$, so the firm's solution will also satisfy the condition when $s$ is sufficiently small. In that case, the open convex region 
defined by (38) will contain all three solutions and the hypotheses of Propositions 4 and 5 will all be satisfied.

In Proposition 3 above, we derived the firm's comparative statics results with respect to $k$ and $p$. We now consider the two remaining parameters $A$ and subjective risk $s$. Substituting the incentive compatibility constraint into (36),

$$
\Pi=(1 / 2) n\left\{\beta\left[A^{2} n(2 p-n \beta)-s \beta\right]-k n\right\}
$$

The optimal incentive is therefore

$$
\beta=\frac{A^{2} n p}{A^{2} n^{2}+s} .
$$

Note that $\beta$ is increasing in $n$ for all $0 \leq n \leq \sqrt{s} / A$ and decreasing thereafter, so an exogenous increase in employment can increase incentives when employment is low. In contrast, Proposition 3 shows that incentives and employment move in opposite directions when team size is endogenous because the budget-breaker never chooses employment in the range $0 \leq n \leq \sqrt{s} / A$. Likewise, an increase in $p$ leads to an increase in $\beta$ when $n$ is exogenous (as in standard agency theory) but not when it is endogenous.

Substituting (40) into (39), we obtain the firm's expected profits

$$
\Pi=\frac{n^{2}\left(A^{4} p^{2} n-A^{2} k n^{2}-k s\right)}{2\left(A^{2} n^{2}+s\right)}
$$

solely as a function of employment $n$. From (41), it is a simple matter to solve for the maximizer $n_{b}$ numerically. ${ }^{9}$

Numerical Result 1. (i) An increase in $A$ or $p$ increases $n, T$, and expected pay $\alpha+\beta y$ and decreases $\beta$. (ii) An increase in $k$ increases $\beta$ and decreases $n, T$, and expected pay. (iii) An increase in $s$ decreases $\beta, T$, and expected pay and increases $n$.

An improvement in productivity $A$ (e.g., an investment in machinery) or an increase in price $p$ leads to an increase in employment $n$ and effort $T$ because these parameters and

9 Although Mathematica does provide a closed-form solution for (41), the expression is complicated and ill-behaved because of rounding errors. We instead used Solve to find the zeros of the first-order condition for (41) and chose the largest one in accordance with the proof of Lemma 4 . We then substituted the global maximizer $n_{b}$ into (40) to find $\beta_{b}$ and both solutions into the incentive compatibility constraint to find $T_{b}$. The Mathematica notebook is available at http://web.me.com/mtrauh/Site/Welcome.html. 
variables are complementary in production. At the same time, the budget-breaker reduces incentives $\beta$ which are substitutes for employment. A decrease in subjective risk $s$ (e.g., an improvement in monitoring technology which makes performance easier to measure) leads to stronger incentives $\beta$ because of the risk-reward tradeoff and a reduction in employment. The overall effect is to increase effort. ${ }^{10}$

These results are consistent with a constellation of stylized facts related to firm size, measured in terms of employment. As previously discussed, size is positively correlated with division of labor and vertical differentiation (see section 1) and negatively correlated with incentives (this section). Large firms also tend to pay higher wages, which is referred to as the size-wage effect. For example, Brown and Medoff (1989) find that establishment and company size have independent positive effects on wages and that worker quality only explains about one-half of the size premium. Kalleberg and Van Buren (1996) note that large firms tend to be more capital intensive (p. 50) and find that size, wages, formalization (explicit rules and procedures), and industry concentration are all positively correlated. Our comparative statics results are consistent with these findings if greater capital intensity is associated with higher $A$ and greater concentration with higher prices $p$ because such firms will be larger; with greater specialization and a more extensive division of labor; higher transaction costs (e.g., formalization and vertical differentiation); weaker incentives; and higher wages.

Note that most of these correlations vanish in the Kalleberg and Van Buren regressions which control for size. Likewise, Brown and Medoff find that concentration (proxied by industry dummies) has no effect on the size-wage relationship. The problem with such regressions which include size as an independent variable is that size is endogenous and may therefore soak up the explanatory power of the parameters. We should also point out that not all of our results are consistent with the empirical literature. A notable exception is the finding by Kalleberg and Van Buren that wages are positively correlated with the

\footnotetext{
10 We were unable to prove the comparative statics results for $A$ in the context of Proposition 3 above because we have not been able to show that the incentive compatibility constraint is increasing in $A$ in the sense of Veinott (see Vives (1999, p. 23)). Since the relevant cross-partial conditions do not hold (see (iii) where $n$ and $T$ move in opposite directions), we cannot use the lattice programming methods of Proposition 3 to derive the comparative statics results for subjective risk $s$. In both cases, we were therefore forced to resort to numerical methods.
} 
difficulty of measuring performance, whereas in our model expected pay is decreasing in subjective risk.

In The Modern Firm, Roberts (2004) documents relatively recent fundamental shifts in firms' strategies and organizational structures driven by increased global competition, more demanding capital markets, and technological advances in communication, data processing, flexible production technologies, and transportation (also see Lindbeck and Snower (1996, 2000)). The main features of the new paradigm include: outsourcing and a focus on the firm's core competencies; cooperative relationships with external suppliers; within the firm, small business units and more intensive incentives; a shift away from mass production (specialization, division of labor, and returns to scale) towards modern manufacturing (short production runs, broad human capital, and employee initiative); downsizing and delayering (e.g., fewer hierarchical layers); and training and development. An example of the old paradigm is Ford in the Model T era, while Toyota exemplifies the new (Roberts (2004, p. 48-49)).

Our model is too simple to capture all of these aspects, but it does address the two central themes related to incentives and the division of labor. In our model, a reduction in price $p$ due to an increase in competition would lead to an increase in incentives and a decrease in specialization and division of labor. Roberts himself suggests that improved information and data-processing systems have made performance measurement easier and tipped the risk-reward tradeoff in the direction of stronger incentives. The same effect is also present in our model, where a reduction in $\sigma^{2}$ with risk aversion $r$ held constant decreases subjective risk $s=r \sigma^{2}$ and increases incentives, but also reduces specialization and the division of labor. A coarser division of labor should also result in delayering and a reduction in the transaction costs associated with communication, coordination, and supervision. To be consistent with these trends, these forces would have to be stronger than those associated with improvements in communication (a reduction in $k$ ), which would have the opposite effect on incentives and employment.

Lindbeck and Snower $(1996,2000)$ are concerned with the same issue as this paper: the division of labor within the firm. In their model, there are two types of workers, 1 and 2, and two tasks, 1 and 2, which are complementary in production. A type $i$ 
worker has a comparative advantage in the performance of task $i$ (workers are otherwise identical). After paying the workers' reservation wage, the firm allocates them between the two tasks. This allocation is determined by three forces: (i) the gains from specialization, (ii) informational task complementarities (productivity in one task is increasing in the time spent on the other), and (iii) workers' preferences for specialization (as reflected in the reservation wage). A Tayloristic organization is one where type $i$ workers completely specialize in task $i$; otherwise the organization is holistic. The authors explain the current trend towards holism in terms of a reduction in the gains from specialization, stronger informational task complementarities, stronger preferences for diverse work, and broader human capital. Their paper is highly complementary to ours in that they consider different tradeoffs (e.g., informational task complementarities and preferences for diversity in work), whereas in this paper we incorporate moral hazard and focus on the tradeoff between incentives and specialization.

\section{Conclusion}

In this paper, we extended the classical teams framework in Holmström (1982) to the case where team size is endogenous. Our results essentially reverse Alchian and Demsetz (1972) and Holmström, but are consistent with a sizable body of empirical evidence. A reappraisal of the institutions of partnership and firm is therefore warranted. In Becker and Murphy (1992), the social planner faces a tradeoff between the gains from specialization and the transaction costs associated with larger teams. In our model, the optimal partnership size balances the risk-reward and Becker-Murphy tradeoffs, where the latter is distorted by the $1 / n$ problem. Contrary to Alchian and Demsetz, in our model partnerships are not necessarily small, either in absolute terms or in comparison with the first best, nor are they necessarily characterized by shirking. As in Legros and Matthews (1993), equal division is a high-powered incentive in the sense that it implements the first best effort-employment relationship. Our comparative statics results provide a simple explanation for the size distribution of partnerships documented in Garicano and Hubbard (2009). The model complements the theory of referrals in Garicano and Santos (2004) and worker selection in Levin and Tadelis (2005). 
The firm acquires two novel characteristics when team size is endogenous and workers can specialize within a division of labor: (i) the budget-breaker can increase effort with an increase in incentives and/or specialization and (ii) incentives and employment are substitutes. The latter implies that incentives decline with firm size, which is consistent with some evidence. In Holmström, the role of the budget-breaker is to promote efficiency with high-powered incentives, which is inconsistent with the stylized fact that incentives are weak in firms. In contrast, in our model the budget-breaker offers incentives that are weaker than first best and optimal equal-division incentives, so shirking is more prevalent in firms than in partnerships. These results reverse the classical depictions of the firm and partnership. Since incentives and team size are substitutes, the budget-breaker increases

employment above the first best and optimal partnership levels, so firms are inefficiently large. In our model, the role of the budget-breaker is to reduce agents' exposure to risk and to promote and coordinate specialization and the division of labor rather than to offer high-powered incentives. Our comparative statics results are consistent with the empirical findings that firm size, wages, specialization and division of labor, capital intensity, and industry concentration are positively correlated. They are also consistent with recent organizational trends towards more intensive incentives and a reduced emphasis on returns to scale, specialization, and division of labor.

\section{Appendix}

\section{Proof of Proposition 1}

We first prove (i). Fix $0<n \leq N$. From (8), efficiency requires $T_{i} / \rho_{i}=R$ for all $i$ for some constant $R$. Given any such $\left\{\rho_{i}\right\}$ and $\left\{T_{i}\right\}$, consider the alternative $\bar{T}=R / n$ and $\bar{\rho}=1 / n$ which produces the same expected output. By Jensen's inequality,

$$
C(\bar{T})=C(R / n)=C\left[\sum_{i}(1 / n)\left(\rho_{i} R\right)\right] \leq(1 / n) \sum_{i} C\left(\rho_{i} R\right)=(1 / n) \sum_{i} C\left(T_{i}\right)
$$

and

$$
n C(\bar{T}) \leq \sum_{i} C\left(T_{i}\right)
$$


so we can restrict attention to an equal division of labor $\rho_{i}=1 / n$ and $T_{i}$ the same for all $i$. The problem is now to choose $n$ and $T$ to maximize

$$
p \frac{A}{\theta}(n T)^{\theta}-n C(T)-K(k, n) .
$$

Differentiating with respect to $T$,

$$
p A n(n T)^{\theta-1}-n C^{\prime}(T)=n T^{\theta-1}\left[p A n^{\theta-1}-f(T)\right] .
$$

Under Assumptions 1, (A.3) has a local minimum at $T=0$, increases up to its global maximum at (13), and then decreases thereafter. To prove (ii), we substitute

$$
T(n)=\left(p A n^{\theta-1}\right)^{\frac{1}{2-\theta}}
$$

(10), and (11) into (A.3),

$$
V(n)=(1 / 2) n^{2}\left[\frac{2-\theta}{\theta}(A p)^{\frac{2}{2-\theta}} n^{\frac{3 \theta-4}{2-\theta}}-k\right]
$$

$V(n)$ has two zeros, $n=0$ and $n=n_{f}^{0}$ defined in (14). Differentiating,

$$
V^{\prime}(n)=(1 / 2) n\left[(A p)^{\frac{2}{2-\theta}} n^{\frac{3 \theta-4}{2-\theta}}-2 k\right]
$$

with critical points $n=0$ and $n=n_{f}^{c}$ defined in (15). If $4 / 3<\theta<2$ the exponent $(3 \theta-4) /(2-\theta)$ in $(\mathrm{A} .6)$ and $(\mathrm{A} .7)$ is positive. It follows that $V(n)$ is negative between $n=0$ and $n=n_{f}^{0}$ and then positive, increasing, and unbounded thereafter. In that case, $n_{f}=0$ when $N<n_{f}^{0}$ and $n_{f}=N$ otherwise. If $1 \leq \theta<4 / 3$ then $V(n)$ is positive between $n=0$ and $n=n_{f}^{0}$ and then negative, decreasing, and unbounded thereafter. From (A.7), the slope of $V(n)$ is positive and then negative, so $n_{f}^{c}$ is the unique global unconstrained maximum. It is the constrained maximum when it satisfies $0<n \leq N$. From (A.6), the condition in (16) ensures nonnegative expected total surplus when $n=1$, so the social planner operates. 


\section{Proof of Lemma 1}

We first prove (i). Given the choices of the other agents, let $y_{-i}=\inf _{s \in S / S_{i}} q_{s}$ (the infimum over all other agents' tasks) and

$$
T_{y_{-i}}=\rho_{i}\left(\frac{\theta y_{-i}}{A}\right)^{1 / \theta}
$$

the minimum total effort necessary for agent $i$ to produce $y_{-i}$ [the solution to (8)]. The agent's certainty equivalent payoff is

$$
U_{i}=\alpha_{i}+\beta_{i} \frac{A}{\theta}\left(\frac{T_{i}}{\rho_{i}}\right)^{\theta}-C\left(T_{i}\right)-(1 / 2) s \beta_{i}^{2}
$$

when $T_{i} \leq T_{y_{-i}}$ and

$$
U_{i}=\alpha_{i}+\beta_{i} y_{-i}-C\left(T_{i}\right)-(1 / 2) s \beta_{i}^{2}
$$

otherwise. Differentiating (A.9) with respect to $T_{i}$,

$$
\frac{A \beta_{i} T_{i}^{\theta-1}}{\rho_{i}^{\theta}}-C^{\prime}\left(T_{i}\right)=T_{i}^{\theta-1}\left[\frac{A \beta_{i}}{\rho_{i}^{\theta}}-f\left(T_{i}\right)\right] .
$$

Given our assumptions on $f$ in Assumptions 1, it is clear that (A.9) has a local minimum at $T_{i}=0$ and a global maximum at

$$
T_{\beta_{i}}=g\left(\frac{A \beta_{i}}{\rho_{i}^{\theta}}\right) .
$$

The agent's best response is therefore $T_{\beta_{i}}$ when $T_{\beta_{i}} \leq T_{y_{-i}}$ and $T_{y_{-i}}$ otherwise. Clearly, $\left\{T_{i}\right\}$ is a Nash equilibrium which generates expected output $y$ iff $T_{i}=T_{i, y}$ and $T_{i, y} \leq T_{\beta_{i}}$

for all $i$, where $T_{i, y}$ is the minimum total effort by $i$ necessary to produce $y$. We can re-write $T_{i, y} \leq T_{\beta_{i}}$ as $y \leq Y_{i}$ for all $i$, where

$$
Y_{i}=\frac{A}{\theta}\left[\frac{1}{\rho_{i}} g\left(\frac{A \beta_{i}}{\rho_{i}^{\theta}}\right)\right]^{\theta} .
$$

It follows that there exists a continuum of Nash equilibria corresponding to each $y$ such that $0 \leq y \leq \min _{i} Y_{i}$. Since $T_{i, y}$ is increasing in $y$ and each agent wants to be as close to $T_{\beta_{i}}$ as possible, the Pareto dominant equilibrium corresponds to $y=\min _{i} Y_{i}$. We now prove (ii). If $\beta_{i}=\beta$ and $\rho_{i}=1 / n$ for all $i$ then $Y_{i}$ is the same for all $i, y=Y_{i}$ and $T_{i, y}=T_{\beta}$ 
for all $i$ at the Pareto dominant equilibrium, and (20) follows from (A.12). To prove (iii), substitute $\beta=p / n$ into (20) and compare with (13).

\section{Proof of Proposition 2}

From (21) and (A.6),

$$
U^{p}=(1 / 2)\left[\left(\frac{2-\theta}{\theta}\right)(A p)^{\frac{2}{2-\theta}} n^{\frac{2(\theta-1)}{2-\theta}}-k n-s\left(\frac{p}{n}\right)^{2}\right] .
$$

Differentiating with respect to $n$,

$$
U_{n}^{p}=(1 / 2)\left[\frac{2(\theta-1)}{\theta} \frac{(A p)^{\frac{2}{2-\theta}}}{n^{\frac{4-3 \theta}{2-\theta}}}+\frac{2 s p^{2}}{n^{3}}-k\right] .
$$

This is strictly decreasing in $n$ so $U^{p}$ is strictly concave in $n$. Since $U_{n}^{p}>0$ for $n$ sufficiently small and $U_{n}^{p}<0$ for $n$ sufficiently large, $U^{p}$ has a unique global maximizer $n_{p}^{*}$. The comparative statics results in (i) are clear by inspection of (A.15). To prove (ii), substitute $n_{f}^{c}$ in (15) into (A.15),

$$
U_{n}^{p}=s\left[\frac{(2 k)^{3(2-\theta)}}{A^{6} p^{2(3 \theta-1)}}\right]^{\frac{1}{4-3 \theta}}-k\left(\frac{4-3 \theta}{2 \theta}\right) .
$$

Since $U^{p}$ is strictly concave in $n, n_{f}<n_{p}$ iff (A.16) is positive and $n_{p}<n_{f}$ iff (A.16) is negative. Re-arranging (A.16) yields (24).

\section{Proof of Lemma 2}

The expression in (22) is obtained from (A.15) with $s=0$.

\section{Proof of Lemma 3}

Fix $n>0$. Given $\left\{\beta_{i}\right\}$ and $\left\{\rho_{i}\right\}$, let $\left\{T_{i}\right\}$ be the corresponding Pareto dominant equilibrium with expected output $y$. From the proof of Lemma $1, T_{i}=T_{i, y}$ and $T_{i, y} \leq T_{\beta_{i}}$ for all $i$, with equality for those agents with $T_{\beta_{i}}=\min _{j} T_{\beta_{j}}$. The budget-breaker can reduce each $\beta_{i}$ until $T_{i, y}=T_{\beta_{i}}$ or

$$
\beta_{i}=\frac{\rho_{i}^{\theta} f\left(\rho_{i} z\right)}{A}
$$


for all $i$, where

$$
z=\left(\frac{\theta y}{A}\right)^{\frac{1}{\theta}}
$$

(see (A.8) and (A.12)). This increases expected profit in (27) by reducing the agents' risk premia without affecting efforts $\left\{T_{i}\right\}$ or expected output $y$. Define $\bar{\rho}=1 / n, \bar{T}=z / n$, and

$$
\bar{\beta}=\frac{f(\bar{T})}{A n^{\theta}} .
$$

Substituting $\bar{\beta}$ into (20), the Pareto dominant equilibrium is $T_{i}=\bar{T}$ for all $i$. Substituting $\bar{T}$ into (8), expected output is the same as before. We now compare expected profit under $\bar{\rho}, \bar{\beta}$, and $\bar{T}$ versus the initial task assignments $\left\{\rho_{i}\right\}$, the improved incentives $\left\{\beta_{i}\right\}$ in (A.17), and $\left\{T_{i}\right\}$. We have (A.2) as before. We now substitute (A.17)

$$
\sum_{i} \beta_{i}^{2}=\left(1 / A^{2}\right) \sum_{i} \rho_{i}^{2 \theta} f^{2}\left(\rho_{i} z\right)
$$

Differentiating the summand in (A.20) twice with respect to $\rho_{i}$,

$$
2 \rho_{i}^{2(\theta-1)}\left[\theta(2 \theta-1) f^{2}+\rho_{i}^{2} z^{2}\left(f^{\prime}\right)^{2}+\rho_{i} z f\left(4 \theta f^{\prime}+\rho_{i} z f^{\prime \prime}\right)\right] .
$$

It follows from (28) that the summand is convex in $\rho_{i}$ and from theorems 1 and 3 in Encaoua and Jacquemin (1980) that (A.20) is minimized at $\rho_{i}=\bar{\rho}$ or $\beta_{i}=\bar{\beta}$. The alternative $\bar{\rho}$, $\bar{\beta}$, and $\bar{T}$ therefore produces the same expected output with lower costs and lower risk premia.

Since the derivative is defined on open sets and $S$ in (31) is not open, we need definitions for "supermodularity" and "increasing differences" which make no reference to differentiation. Let $\mathbf{R}$ be the space of real numbers. If $x=\left(x_{1}, \ldots, x_{n}\right)$ and $y=\left(y_{1}, \ldots, y_{n}\right)$ are vectors in $\mathbf{R}^{n}$ then $x \geq y$ iff $x_{i} \geq y_{i}$ for all $i$. Let $X \subseteq \mathbf{R}^{n}$. If $x, y \in X$ then when they exist

$$
\begin{aligned}
& x \vee_{X} y=\sup _{X}\{x, y\} \\
& x \wedge_{X} y=\inf _{X}\{x, y\} .
\end{aligned}
$$

$X$ is a lattice if $x \vee_{X} y$ and $x \wedge_{X} y$ exist and are in $X$ for all $x, y \in X . X$ is a sublattice if $x \vee_{\mathbf{R}^{n}} y$ and $x \wedge_{\mathbf{R}^{n}} y$ are in $X$ for all $x, y \in X$. If $X$ is a lattice then $f: X \rightarrow \mathbf{R}$ is supermodular iff

$$
f\left(x \vee_{X} y\right)+f\left(x \wedge_{X} y\right) \geq f(x)+f(y)
$$


for all $x, y \in X$. If $T \subseteq \mathbf{R}^{m}$ then $f: X \times T \rightarrow \mathbf{R}$ has increasing differences on $X \times T$ iff $f(x, t)-f\left(x, t^{\prime}\right)$ is increasing in $x$ for all $t \geq t^{\prime}$. If $f$ is twice continuously differentiable on $X \times T$ these definitions are equivalent to the ones in the text. Standard references on these topics include Milgrom and Roberts (1990), Vives (1999), and Topkis (1998).

\section{Proof of Proposition 3}

Since $S$ is not open, the idea of the proof is to use the relevant cross-partials to establish supermodularity and increasing differences on a set $\tilde{S}$ where $\Pi$ is differentiable and then restrict the constraint set to $S \subseteq \tilde{S}$. The problem is to choose $(\beta, n, T)$ to maximize (29) subject to $\beta \geq 0, n \geq 0, T \geq 0$, and incentive compatibility (20). Substituting (20) into $(29)$

$$
\Pi_{\beta}=p A n^{\theta+1} g^{\prime}\left[A(n g)^{\theta-1}-C^{\prime}\right]-n s \beta
$$

Assuming a unique interior solution,

$$
A(n g)^{\theta-1}-C^{\prime}>0 \quad \Longleftrightarrow \quad T=g\left(A n^{\theta} \beta\right)<g\left(A n^{\theta-1}\right)
$$

so the optimum lies in $S$ for all $A, k, p, s>0$.

The relevant cross-partials of (29) are

$$
\begin{array}{ccc}
\Pi_{\beta n}=-s \beta \leq 0 & \Pi_{n T}=p A \theta(n T)^{\theta-1}-C^{\prime} & \Pi_{\beta T}=0 \\
\Pi_{\beta k}=0 & \Pi_{n k}=-K_{n k} \leq 0 & \Pi_{T k}=0 \\
\Pi_{\beta p}=0 & \Pi_{n p}=A n^{\theta-1} T^{\theta} \geq 0 & \Pi_{T p}=A n^{\theta} T^{\theta-1} \geq 0 .
\end{array}
$$

Since

$$
\Pi_{n T} \geq 0 \quad \Longleftrightarrow \quad T \leq g\left(p A \theta n^{\theta-1}\right)
$$

after the change of variables $z=1 / \beta$ and $w=1 / k$ the cross-partials have the appropriate signs on $\tilde{S} \times(0, \infty) \times(0, \infty)$, where $\tilde{S}$ is defined by $z>0, n>0, T>0$, and (A.27). It is easy to show that $n>0, T>0$, and (A.27) define a sublattice in $\mathbf{R}^{2}$ because $g$ is strictly increasing. Since a product of sublattices is a sublattice, $\Pi$ is supermodular in $(z, n, T)$ with increasing differences in $(z, n, T)$ and $(p, w)$ on $\tilde{S} \times(0, \infty) \times(0, \infty)$. 
We now show that $S$ in $(31)$ is a lattice. Let $\left(z_{1}, n_{1}, T_{1}\right),\left(z_{2}, n_{2}, T_{2}\right) \in S$ and $n_{1} \geq n_{2}$ without loss of generality. We need to show that

$$
\left(z_{1}, n_{1}, T_{1}\right) \vee_{S}\left(z_{2}, n_{2}, T_{2}\right) \in S
$$

Note that $h$ in (30) is strictly increasing in $n$ and weakly decreasing in $z$. We first consider the case $z_{1} \geq z_{2}$. If $T_{1} \geq T_{2}$ the supremum is clearly $\left(z_{1}, n_{1}, T_{1}\right) \in S$. If $T_{1}<T_{2}$ the supremum is $\left(z_{1}, n_{3}, T_{2}\right)$, where $n_{3}>n_{1}$ is defined by $T_{2}=h\left(z_{1}, n_{3}\right)$. Now consider the case $z_{2}>z_{1}$, which implies $T_{1} \geq T_{2}$. Let $T_{3}=h\left(z_{2}, n_{1}\right) \leq T_{1}$. If $T_{3}=T_{1}$ the supremum is $\left(z_{2}, n_{1}, T_{1}\right)$. If $T_{3}<T_{1}$ the supremum is $\left(z_{2}, n_{3}, T_{1}\right)$, where $n_{3}>n_{1}$ and $T_{1}=h\left(z_{2}, n_{3}\right)$. The proof for the infimum is similar, which completes the proof of (i).

If $p \theta \geq 1$ then $g\left(A n^{\theta-1}\right) \leq g\left(p A \theta n^{\theta-1}\right)$ and $S \subseteq \tilde{S}$, which proves (ii). Finally, (iii) follows from an application of theorem 2.3 in Vives (1999, p. 26) (where $S=X$ in his notation and statement).

\section{Proof of Proposition 4}

Let

$$
V(n, T)=p \frac{A}{\theta}(n T)^{\theta}-n C(T)-K(k, n),
$$

the first best expected surplus with the same effort for all agents and an equal division of labor as in Proposition 1(i). We can re-write (33) as

$$
\Pi(n, T)=V(n, T)-\frac{s f^{2}}{2 A^{2} n^{2 \theta-1}} .
$$

Differentiating with respect to $n$ and $T$,

$$
\begin{aligned}
& \Pi_{n}=V_{n}+\frac{(2 \theta-1) s f^{2}}{2 A^{2} n^{2 \theta}} \\
& \Pi_{T}=V_{T}-\frac{s f f^{\prime}}{A^{2} n^{2 \theta-1}} .
\end{aligned}
$$

The expression in (A.31) is positive and that in (A.32) negative at the first best solution $\left(n_{f}, T_{f}\right)$ because $1 \leq \theta<4 / 3, f^{\prime}>0$, and $V_{n}=V_{T}=0$. Since (33) is strictly concave on an open convex neighborhood of both solutions, $T_{b}<T_{f}$ and $n_{b}>n_{f}$. From (13) and $(20)$

$$
T_{b}<T_{f} \Longleftrightarrow \beta_{b}<\frac{p}{n_{b}}\left(\frac{n_{f}}{n_{b}}\right)^{\theta-1}<\frac{p}{n_{f}}
$$


which completes the proof.

\section{Proof of Proposition 5}

We re-write $(33)$ as

$$
\Pi(n, T)=n U^{p}(n, T)+(1 / 2) s\left(\frac{p^{2}}{n}-\frac{f^{2}}{A^{2} n^{2 \theta-1}}\right)
$$

where

$$
U^{p}(n, T)=(p / n)(A / \theta)(n T)^{\theta}-C(T)-(1 / 2) s(p / n)^{2}-(1 / n) K(k, n) .
$$

Since

$$
\Pi_{T}=n U_{T}^{p}-\left(\frac{s f f^{\prime}}{A^{2} n^{2 \theta-1}}\right)
$$

$\Pi_{T}<0$ at the EDP solution. Since

$$
\Pi_{n}=n U_{n}^{p}+U^{p}+(1 / 2) s\left[\frac{(2 \theta-1) f^{2}}{A^{2} n^{2 \theta}}-\frac{p^{2}}{n^{2}}\right]
$$

and $U_{n}^{p}=0$ and $U^{p} \geq 0$ at the EDP solution, we focus on the term in square brackets.

$$
\frac{(2 \theta-1) f^{2}}{A^{2} n^{2 \theta}}-\frac{p^{2}}{n^{2}}=(2 \theta-1) \beta^{2}-\frac{p^{2}}{n^{2}}=\frac{(2 \theta-1) p^{2}}{n^{2}}-\frac{p^{2}}{n^{2}}=\frac{2 p^{2}(\theta-1)}{n^{2}} \geq 0
$$

because $\beta=p / n$ for an EDP.

Before proving Lemma 4, we recall some facts about strictly quasi-concave functions. Let $X \subseteq \mathbf{R}^{n}$ be open and convex and $f: X \rightarrow \mathbf{R}$ twice continuously differentiable. First, $f$ is strictly quasi-concave on $X$ if for all $x \in X$ its Hessian (the matrix of second-order partial derivatives) evaluated at $x$ is negative definite on the tangent to the level set of $f$ through $x$. It follows that, in one dimension, $f$ is strictly quasi-concave if $f^{\prime \prime}<0$ wherever $f^{\prime}=0$. If $X \subseteq \mathbf{R}$ then $f$ is strictly quasi-concave iff either it is increasing, decreasing, or increasing for all $x<x^{*}$ and decreasing for all $x>x^{*}$. Similar statements hold for strictly quasi-convex functions. 


\section{Proof of Lemma 4}

We start with (41) in the text. If (37) holds then (41) has three zeros

$$
n=0, \quad n_{b 1}=\frac{A^{3} p^{2}-\sqrt{A^{6} p^{4}-4 s k^{2}}}{2 A k}, \quad \text { and } \quad n_{b 2}=\frac{A^{3} p^{2}+\sqrt{A^{6} p^{4}-4 s k^{2}}}{2 A k}
$$

where $\Pi<0$ on $\left(0, n_{b 1}\right), \Pi>0$ on $\left(n_{b 1}, n_{b 2}\right)$, and $\Pi<0$ and diverges to $-\infty$ on $\left(n_{b 2}, \infty\right)$. Since $\Pi$ is continuous and $\left[n_{b 1}, n_{b 2}\right]$ is compact, a global maximum with positive expected profits exists on $\left(n_{b 1}, n_{b 2}\right)$. Differentiating (41),

$$
\Pi_{n}=\frac{n h}{2\left(A^{2} n^{2}+s\right)^{2}},
$$

whose sign is determined by

$$
h=A^{6} p^{2} n^{3}-4 A^{2} k s n^{2}-2 k s^{2}+A^{4} n\left(3 p^{2} s-2 k n^{3}\right) .
$$

Setting (A.41) equal to zero, solving for $k$, and substituting,

$$
\Pi_{n n}=-\frac{A^{4} p^{2} n\left(A^{4} n^{4}+6 A^{2} n^{2} s-3 s^{2}\right)}{2\left(A^{2} n^{2}+s\right)^{3}} .
$$

This expression has zeros at $n=0$ and

$$
n_{q}=\left[\frac{(2 \sqrt{3}-3) s}{A^{2}}\right]^{1 / 2}
$$

It follows that $\Pi$ is strictly quasi-convex on $\left(0, n_{q}\right)$ and strictly quasi-concave on $\left(n_{q}, \infty\right)$. Since $\Pi$ is decreasing near $n=0$, it cannot be increasing on $\left(0, n_{q}\right)$. Suppose it is decreasing. In that case, $\Pi$ is negative at $n_{q}$ and $n_{q}<n_{b 1}$. Since $\Pi$ is increasing at $n=n_{b 1}$, decreasing at $n=n_{b 2}$, and strictly quasi-concave on $\left(n_{q}, \infty\right)$, it must increase from $n_{q}$ up to a unique global maximum and then decrease thereafter. It follows that $n_{q}$ is a local minimum where $\Pi_{n n}>0$, a contradiction. We conclude that $\Pi$ decreases to a local minimum on $\left(0, n_{q}\right)$, then increases to a unique global maximum, and then decreases thereafter, which proves (i). Differentiating (33),

$$
\begin{aligned}
& \Pi_{T T}=-\left(n+\frac{s}{A^{2} n}\right)<0, \\
& \Pi_{n n}=-\left(k+\frac{s T^{2}}{A^{2} n^{3}}\right)<0,
\end{aligned}
$$


and

$$
\Pi_{T T} \Pi_{n n}-\Pi_{n T}^{2}=\frac{A^{2} n^{2}\left[k n-(A p-T)^{2}\right]+s[k n-T(2 A p-3 T)]}{A^{2} n^{2}} .
$$

If (A.45) is positive then (33) is strictly concave in $n$ and $T$. A sufficient condition is therefore (38) with a weak inequality and

$$
n \geq \frac{T(2 A p-3 T)}{k}
$$

with at least one inequality strict. Since

$$
\frac{(A p-T)^{2}}{k}-\frac{T(2 A p-3 T)}{k}=\frac{(A p-2 T)^{2}}{k} \geq 0
$$

(38) is sufficient. The rest of the proof is supplied in the text.

\section{References}

Alchian, A.A., Demsetz, H., 1972. Production, information costs, and economic organization. Amer. Econ. Rev. 62(5) 777-795.

Bartling, B., von Siemens, F.A., 2011. Equal sharing rules in partnerships. J. Instit. Theor. Econ. 166(2) 299-320.

Becker, G.S., Murphy, K.M., 1992. The division of labor, coordination costs, and knowledge. Quart. J. Econ. 107(4) 1137-1160.

Beyer, J.M., Trice, H.M., 1979. A reexamination of the relations between size and various components of organizational complexity. Admin. Sci. Quart. 24(1) 48-64.

Bolton, P., Dewatripont, M., 2005. Contract Theory. MIT Press, Cambridge, Mass.

Bose, A., Pal, D., Sappington, D.E.M., 2011. On the performance of linear contracts. J. Econ. Man. Strat. 20(1) 159-193.

Bose, A., Pal, D., Sappington, D.E.M., 2010. Equal pay for unequal work: limiting sabotage in teams. J. Econ. Man. Strat. 19(1) 25-53. 
Borghans, L., ter Weel, B., 2006. The division of labor, worker organization, and technological change. Econ. J. 116(509) F45-F72.

Braverman, H., 1974. Labor and Monopoly Capital. Monthly Review Press, New York, NY.

Brown, C., Medoff, J., 1989. The employer size-wage effect. J. Polit. Econ. 97(5) 10271059.

Carter, N.M., Keon, T.L., The rise and fall of the division of labour, the past 25 years. 1986. Organ. Stud. 7(1) 57-74.

Encaoua, D., Jacquemin, A., 1980. Degree of monopoly, indices of concentration, and threat of entry. Int. Econ. Rev. 21(1) 87-105.

Encinosa, W.E., Gaynor, M., Rebitzer, J.B., 2007. The sociology of groups and the economics of incentives: theory and evidence on compensation systems. J. Econ. Behav. Org. $62(2)$ 187-214.

Garicano, L., Hubbard, T.N., 2009. Specialization, firms, and markets: the division of labor within and between law firms. J. Law Econ. Org. 25(2) 339-371.

Garicano, L., Santos, T., 2004. Referrals. Amer. Econ. Rev. 94(3) 499-525.

Gaynor, M., Gertler, P., 1995. Moral hazard and risk spreading in partnerships. RAND J. Econ. 26(4) 591-613.

Holmström, B., 1982. Moral hazard in teams. Bell J. Econ. 13(2) 324-340.

Holmström, B., Milgrom, P., 1991. Multitask principal-agent analyses: incentive contracts, asset ownership, and job design. J. Law Econ. Org. 7(1) 24-52.

Kalleberg, A.L., Van Buren, M.E., Is bigger better? Explaining the relationship between organization size and job rewards. Amer. Soc. Rev. 61(1) 47-66. 
Lang, K., Gordon, P-J., 1995. Partnerships as insurance devices: theory and evidence. RAND J. Econ. 26(4) 614-629.

Legros, P., Matsushima, H., 1991. Efficiency in partnerships. J. Econ. Theory 55(2) 296-392.

Legros, P., Matthews, S.A., 1993. Efficient and nearly-efficient partnerships. Rev. Econ. Stud. 60(3) 599-611.

Levin, J., Tadelis, S., 2005. Profit-sharing and the role of professional partnerships. Quart. J. Econ. 120(1) 131-171.

Liang, P.J., Rajan, M.V., Ray, K., 2008. Optimal team size and monitoring in organizations. The Acc. Rev. 83(3) 789-822.

Lin, Y.J., 1997. Division of labor in teams. J. Econ. Man. Strat. 6(2) 403-423.

Lindbeck, A., Snower, D.J., 1996. Reorganization of firms and labor-market inequality. Amer. Econ. Rev. 86, 315-21.

Lindbeck, A., Snower, D.J., 2000. Multitask learning and the reorganization of work: from Tayloristic to holistic organization. J. Labor Econ. 18, 353-76.

Milgrom, P., Roberts, J., 1990. Rationalizability, learning, and equilibrium in games with strategic complementarities. Econometrica 58, 1255-77.

Prendergast, C., 1999. The provision of incentives in firms. J. Econ. Lit. 37(1) 7-63.

Rasmusen, E., 1987. Moral hazard in risk averse teams. RAND J. Econ. 18(3) 428-435.

Rasmusen, E., Zenger, T., 1990. Diseconomies of scale in employment contracts. J. Law Econ. Org. 6(1) 65-92.

Roberts, J., 2004. The Modern Firm. Oxford University Press, New York, NY. 
Topkis, D.M., 1998. Supermodularity and Complementarity. Princeton University Press, Princeton.

Vives, X., 1999. Oligopoly Pricing. MIT Press, London.

Wallace, M., Kalleberg, A.L., 1982. Industrial transformation and the decline of craft: the decomposition of skill in the printing industry, 1931-1978. Amer. Soc. Rev. 47(3), 307-324. 